\title{
Activating ROS1 Gene Mutation Negative
}

National Cancer Institute

\section{Source}

National Cancer Institute. Activating ROS1 Gene Mutation Negative. NCI Thesaurus.

Code C158069.

A genetic finding indicating that mutations in the ROS1 gene which encode constitutively active forms of the proto-oncogene tyrosine-protein kinase ROS protein are not present in a sample. 